\title{
La Coordinadora de Organizaciones Sindicales (COS): una experiencia de unidad de acción sindical durante la transición
}

\author{
José María Marin Arce
}

Desde la muerte de Franco hasta la consolidación de la democracia, el fortalecimiento de los sindicatos y el largo proceso de reforma sindical estuvieron subordinados al ritmo de las transformaciones políticas. Mientras que la Transición, desde el punto de vista institucional, terminó con la Constitución de 1978, la transición sindical perduró, por lo menos, hasta la aprobación del Estatuto de los Trabajadores en 1980, cuando se reconocieron los derechos individuales de los trabajadores y las normas de negociación colectiva. Como diría Nicolás Redondo:

"Los partidos políticos tenían sus propios problemas y tampoco incidieron mucho para fortalecer el movimiento sindical. El movimiento sindical ha sido el gran sacrificado de la transición. La legalización tuvo lugar en 1977 y las primeras leyes sindicales son de marzo de 1980, el desarrollo del Estatuto de los Trabajadores. No hemos podido prestar todo ese conjunto de servicios que prestan los sindicatos europeos: pagar los subsidios de desempleo, etc. Si a esto añadimos... los errores cometidos por las propias centrales sindicales, que tenian una actividad más política que sindical, se explica que se haya producido un reflujo en parte imputable a nuestro comportamiento" 1.

A finales de 1976, la cuestión del tránsito a la democracia se centró fundamentalmente en quién llevaría la iniciativa política del cambio y cuáles serían las fuerzas políticas que iban a hegemonizar el proceso de transición. El fracaso de la política rupturista permitió que los sectores aperturistas procedentes del franquismo tuvieran un amplio margen de maniobra en la conducción de la reforma ${ }^{2}$, condicionando seriamente el desarrollo del sindicalismo.

Declaraciones de Nicolás Redondo a El Socialista, $n^{\circ} 184,23.12 .80$.

Según JULIÁN ARIZA, secretario de organización de CC.OO.: "la forma en que se está produciendo la ruptura democrática está condicionando sensiblemente el contenido mismo de la de- 
En la forma pactada y controlada en que se llevó a cabo la transición se encuentra la clave explicativa más importante del tipo de relación que se estableció entre sindicalismo y política. Fracasada la ruptura democrática, las cesiones que tuvieron que aceptar los sindicatos fueron muy importantes: por una parte, se bloqueó el desarrollo de la libertad sindical en muchos de sus aspectos, ya que una de las claves del proceso de reforma era impedir la irrupción de las fuerzas sociales en la escena política de la transición, y por otra, se agravó la situación económica y se abandonaron las reformas estructurales tendentes a establecer un modelo económico más acorde con las aspiraciones del movimiento sindical.

Por otra parte, los continuos enfrentamientos entre las grandes centrales sindicales impidieron en gran medida la formación de un frente sindical común ${ }^{3}$ y la diferente estrategia de los sindicatos acabó con el modelo de sindicalismo unitario que había predominado durante los últimos años del franquismo y los primeros momentos de la transición. También terminó el carácter asambleario del movimiento sindical, que tanto había defendido CC.OO., y cada vez fueron menores las movilizaciones de carácter espontáneo y radical que tanto abundaron en los años 1976 y 1977.

Durante toda la transición y gran parte de la consolidación democrática, la única experiencia de unidad de acción sindical, plasmada en un organismo unitario, fue la Coordinadora de Organizaciones Sindicales. La COS, creada a mediados de 1976 por las principales organizaciones sindicales, CC.OO., UGT y USO, a pesar de su corta existencia - se disolvió a primeros de 1977-y de los continuos problemas que surgieron en su

mocracia. Al verificarse el proceso de cambio politico bajo la preponderancia de las fuerzas de la burguesia, buena parte de ellas sostenedoras del régimen anterior, nos encontramos con el hecho innegable de que en gran medida el aparato de poder real sigue en las mismas manos que lo estaba en el régimen franquista". JULIÁN ARIZA: "El sindicalismo ante la crisis económica" en AAVV: Constitución. Economia y Regiones, tomo III, Madrid, Club Siglo XXI, 1978, p. 486. Ver RAFAEL DEL Águila y Ricardo Montero: El discurso de la transición española. Madrid, CIS, 1984, p. 57-58. Jordi Sole Tura: "La constitución y la lucha por el socialismo" en GREGORIO PECES BARBA, JORDI Sole Tura, Miguel Roca Junyent y otros: La izquierda y la Constitución. Barcelona, Taula de Canvi, 1978, p. 20.

3 Nicolás Redondo hacia referencia a los problemas entre CC.OO. y UGT situándolos en un lugar central de la transición sindical. "En primer lugar - dice-tuvimos que enfrentarnos a una patronal incapaz de acomodarse a la nueva situación... Y en segundo lugar, es necesario recordar que no todos los problemas nos llegaron desde el campo empresarial, ya que la otra central sindical mayoritaria ha desplegado movimientos pendulares y contradictorios, movida más por motivaciones partidistas que reivindicativas, que han servido para enturbiar las relaciones en el campo sindical; relaciones que hubieran podido ser fluidas si sus planteamientos ideológicos, intensamente cuestionados desde sus propias bases, no hubieran intentado trasladar la crisis interna del partido Comunista al ámbito estrictamente sindical". Nicolás Redondo: "La transición sindical: una aproximación" en Claridad nº 1, mayo-junio 1984, p. 12. 
seno, tuvo un importante papel en el desarrollo de las movilizaciones obreras, sobre todo en la histórica jornada de paro del 12 de noviembre de 1976, y fue un eficaz instrumento de presión política y sindical en un momento clave de la transición.

\section{FORMACIÓN DE LA COS}

El proceso de unidad de acción entre los sindicatos que culminó con la formación de la cOS fue muy complicado y estuvo lleno de dificultades y desconfianzas. La iniciativa de crear un organismo unitario partió del secretariado de USO ${ }^{4}$, que en febrero de 1976 acordó "establecer relaciones al máximo nivel con CCOO a fin de iniciar conversaciones, ampliables a la UGT y CNT ${ }^{5}$, con vistas a estructurar la unidad de acción basada en: a) la unidad en la lucha reivindicativa, b) la unidad para cambiar el marco político y sindical, y c) la unidad para avanzar en la discusión sobre los problemas del proceso hacia la Unidad Sindical» ${ }^{6}$. A principios de marzo, tuvo lugar una reunión, al máximo nivel, entre CC.OO. y USO en la que se acordó profundizar en la articulación de un organismo unitario e invitar a la UGT a sumarse al proceso de unidad de acción. A mediados de abril, se celebró un encuentro entre CC.OO., USO y UGT para abordar la celebración del $1^{\circ}$ de mayo e iniciar conversaciones para la formación de un órgano conjunto que en principio se llamaría Coordinación Sindical, a imagen y semejanza de la recién formada Coordinación Democrática, organismo unitario de la oposición resultado de la fusión de la Junta Democrática, en la que participaba activamente el PCE, y la Plataforma de Convergencia Democrática, en la que estaba presente el PSOE ${ }^{7}$.

4 En febrero de 1976 hubo algunos contactos entre UGT y CC.OO. para coordinar la lucha sIndical. F. Almendros morcillo, E. Jimenez-Asenjo, F. Pérez Amoros, E. Rojo Torrecll la: El sindicalismo de clase en España (1939-1977), Barcelona, Peninsula, 1978, p. 269. Luis Alonso Novo, dirigente de UGT, se referia a esos contactos entre CCOO y UGT que se habiari celebrado privadamente, sin salir a la luz pública, aunque no especificaba la fecha en que habian tenido lugar. "Rueda de prensa unitaria" en Gaceta de Derecho Social (GDS), separata, n" 59, abril, 1976, p. 28.

- Sobre la negativa de CNT a formar parte de organismos unitarios, ver JUAN GOMEZ CASAS: «Asambleas libres» en Cambio 16, $\mathrm{n}^{\prime} 225,29.3 .76$.

6 Archivo USO: Circular interna $n^{\circ} 7$ del secretariado de USO, 5.6.76. Comunicado del secretariado fechado el 18.2.76, publicado en Lucha Obrera (órgano de USO-Madrid), febrero-marzo, 1976.

La Junta Democrática se presentó públicamente en julio de 1974, como «el organismo de dirección del cambio político". Santiago Minguez Gonzalez: La preparación de la transición a la democracia en España, Zaragoza, Universidad de Zaragoza, 1990, p. 419. Coordinación Democrá- 
Por otra parte, la UGT había propuesto en su congreso de abril de 1976 la creación de una "coordinadora obrera» que estuviera formada por los representantes de todas las organizaciones sindicales, pero con la condición de que previamente hubieran abandonado la OSE y hecho dimitir a los cargos del sindicato vertical ${ }^{8}$. Sin embargo, en las numerosas reuniones que tuvieron las centrales sindicales durante los meses de mayo y junio para la formación de la COS, la UGT no planteó la dimisión de enlaces y jurados. Lo que más importaba en esos momentos a los dirigentes ugetistas era que el futuro organismo no fuera el germen del sindicato unitario que preconizaba CC.OO. ${ }^{9}$. En ese sentido, la Comisión Ejecutiva de UGT alertaba a todos los militantes de las posibles maniobras de CC.OO., tendentes a aprovechar la COS en beneficio de su concepción sindical unitaria $^{10}$.

Si no hubiera sido por el interés del PCE y del PSOE ${ }^{11}$ en consolidar en el ámbito sindical la unidad alcanzada por las fuerzas politicas de oposición, integradas en Coordinación Democrática ${ }^{12}$, y por acelerar la ruptu-

tica, organización que surgió tras los trágicos sucesos de Vitoria, con el fin de establecer un único organismo de toda la oposición, se presentó publicamente el 29 de marzo de 1976. Informaciones. 3.4.76.

9 UGT, n०370, mayo 1976.

9 Ya se encargó la UGT de presentar, en la reunión del 24 de mayo, un documento para la discusión en el que se especificaba que «en ningún momento puede ser considerado a este organismo unitario como una estructura orgánica a partir de la cual se vaya a construir la unidad orgánica de la clase trabajadora". Archivo UGT: Circular de la Comisión Ejecutiva, 7.6.76.

10. "La plataforma unitaria de acción que se va a constituir -decía una circular firmada por Nicolás Redondo- es un organismo de unidad de acción y, en consecuencia, tiene una finalidad primordial; acelerar el proceso hacia la ruptura democrática y sindical, es decir, la conquista de la libertad sindical. En este sentido, hay que tener en cuenta que dicho organismo no puede ser considerado como un embrión orgánico de la unidad orgánica de la clase trabajadora, tal y como señalan las bases de constitución... De ahi que habrá de cuidarse al máximo que los documentos elaborados conjuntamente por CC.OO. y USO, no viertan conceptos contrarios a la naturaleza y finalidad de este Organismo Unitario Sindical". Archivo UGT: Circular de la Comisión Ejecutiva de 13.7.76.

1 La política seguida por CC.OO. y UGT se debe situar en un marco de "una cierta subordinación politica", o mejor dicho partidista, caracteristica consustancial al sindicalismo democrático, aunque no tanto en términos de subordinación sino de vinculación. FaUSTINo Miguelez LoBo: "Las organizaciones sindicales» en FaUStino MIGUélez y CARLOS Prieto: Las relaciones laborales en España, Madrid, Siglo XXI, 1991, p. 213. Álvaro Soto CaRmona: "Comisiones Obreras en la transición y consolidación democrática" en DAvio RuIz (dirección): Historia de Comisiones Obreras (1958-1988), Madrid, Siglo XXI, 1993, p. 454.

12 CC.OO. y UGT pertenecian, desde su creación, a Coordinación Democrática. USO solicitó su ingreso el 12 de junio de 1976, pero manteniendo siempre una actitud muy crítica hacia dicho organismo, pues pretendia desvincular totalmente la COS de Coordinación democrátioa. Archivo USO: Carta del Comité Ejecutivo de USO al Comité Ejecutivo de Coordinación Democrática de 12.6.76 y circular interna $n^{*} 8$ del secretariado de USO, 2.7.76. MANUel ZaguiRRE: "Hacia la coordinadora sindical" en GDS, $n^{\circ} 60$, mayo, 1976. 
ra sindical ${ }^{13}$, posiblemente no hubiera cuajado la formación de la COS, pues el proceso de negociación coincidió con un notable deterioro de las relaciones entre las centrales sindicales. CC.OO. criticaba el favoritismo gubernamental por haber permitido el congreso de la UGT y censuraba las actitudes poco unitarias de la central socialista que estaba torpedeando la creación de la $\cos ^{14}$. Los ugetistas, por su parte, ponían en tela de juicio la viabilidad y la eficacia de un pacto de unidad de acción sindical con CC.OO., sindicato al que acusaban de estar en contra de la libertad sindical y, sobre todo, de querer monopolizar el movimiento sindical, a través de su propuesta de congreso sindical constituyente.

"Las tensiones comenzaron -relata un editorial de la revista UGT- aludiendo a la celebración de nuestro XXX Congreso como si dipusiéramos de licencia especial de tolerancia a cambio de renuncias en nuestros objetivos de desmantelar el verticalismo... Nos calificaron de esqueletos, de fantasmas resucitados. Diciendo que la lucha obrera contra la dictadura comienza cuando se crean nuevos sindicatos y movimientos socio-políticos. Algunos dirigentes de CC.OO., dominados de mesianismo, se sienten llamados por la historia a ocupar la cabeza del movimiento obrero español...Valoramos profundamente la unidad de la clase trabajadora... pero unidad que no es la que quieren los dirigentes de CC.OO... la única unidad que hemos tenido es la impuesta por el verticalismo; en definitiva están olvidando que la libertad sindical es un derecho fundamental...Otro motivo de desacuerdo entre las organizaciones sindicales democráticas ha sido la concepción que CC.OO tiene de la asamblea de los trabajadores... Para qué firmar acuerdos en los que las relaciones entre los firmantes se basan en la lealtad y respeto mutuo, si los compañeros están soportando actitudes agresivas de los miembros de una de las organizaciones firmantes. Creemos que la situación es grave. Sin embargo, ante los intentos desesperados de alguna organización de monopolizar, a la portuguesa, a la clase trabajadora española, la UGT ha decidido actuar con coherencia y apoyar la creación de un organismo sindical de unidad de acción que sirva para el fortalecimiento de la clase trabajadora española» 15.

A pesar de este memorial de agravios contra CC.OO., las conversaciones transcurrieron con cierta normalidad hasta la reunión del 15 de junio en la que CC.OO., UGT y USO firmaron un comunicado conjunto

13 Ver declaraciones de LuIS ALonso Novo en "Rueda de prensa" en GDS, $n^{\circ}$ 59, separata, abril 1976, p. 27.

14 Como respuesta a las críticas de CC.OO. a la forma en que se habia celebrado el congreso de UGT, la central socialista declinó la invitación de CG.OO. para asistir a su proyectada Asamblea Nacional que se celebraria en julio de 1976. La justificación de UGT, sin embargo, fue el desacuerdo con los procedimientos empleados por CC.OO. para elegir los delegados a la Asamblea Nacional. Archivo UGT: Circular n²2 de la Comisión Ejecutiva de UGT, julio 1976.

is UGT, na 372, julio-agosto 1976. 
anunciando la creación de una "Coordinadora de Fuerzas Sindicales". A partir de esa fecha se agudizaron los problemas, en su mayoria derivados de la insistencia de CC.OO. en promover un congreso sindical constituyente y de la campaña promovida en las empresas para elegir los delegados que asistirían a la Asamblea Nacional de CC.OO., prevista para el mes de julio ${ }^{16}$.

A trancas y barrancas continuaron las negociaciones, unas veces dificultadas por UGT, que seguía recelando de CC.OO., y otras veces por USO, que aducía problemas de organización interna para refrendar los acuerdos alcanzados ${ }^{17}$. Por fin, el 22 de julio, UGT, USO y CC.OO. decidieron la constitución de la Coordinadora de Organizaciones Sindicales (COS), acordando que su presentación pública se haría durante la primera semana de septiembre, siguiendo un plan meticulosamente preparado, basado en ruedas de prensa, mítines, actos conjuntos, etc. tanto en el territorio nacional como en el extranjero ${ }^{18}$.

Pero la firma del acuerdo no supuso el final de las desconfianzas entre UGT y CC.OO. El día 24 de julio, dos días después de formarse la COS, la UGT advertia de las tácticas oportunistas y deshonestas de CC.OO. para convertirla en un sindicato unitario y pedía a los militantes mantener una cactitud tensa, vigilante y ofensiva que desmonte todo intento manipulador de CC.OO.» ${ }^{19}$.

Al mismo tiempo que se desarrollaba este proceso unitario en torno a la COS, en Cataluña se revitalizaba la antigua Alianza Sindical que agrupaba a CNT, SOC y UGT. Este organismo no era mas que un frente sindical contra CC.OO. para luchar eficazmente contra la posición hegemónica del sindicato comunista en Cataluña ${ }^{20}$.

16 Archivo UGT: Resolución de la Comisión Ejecutiva de UGT, 16.6.76 y circular $n^{\circ} 18$ de la Comisión Ejecutiva de UGT de 16.6.76. Frente a los ataques de UGT, Nicolás Satorius defendia el derecho de CC.OO. de celebrar asambleas de trabajadores, fueran o no militantes de la organización, y de preparar como quisieran la asamblea de Barcelona. GDS, n 62, julio-agosto 1976, p. 28.

Tras la reunión del 15 de junio se celebraron otras tres, los dias 30.6.76, 8.7.76 y 22.7.76. Archivo UGT: Circular $n^{\circ} 22$ de la Comisión Ejecutiva de YGT, julio 1976. En la reunión del 8 de julio, se llegó a un acuerdo definitivo sobre los elementos constitutivos del organismo unitario y se aprobaron dos documentos importantes: una plataforma reivindicativa común y las bases para la es. tructuración y funcionamiento de la coordinadora sindical. GDS, $n^{\circ}$ 62-63, julio-agosto 1976, p. 27.

${ }_{18}$ El 11 de septiembre se daba a conocer publicamente en Madrid la COS. GDS, $\mathrm{n}^{\circ} 63$, separata, septiembre 1976. Archivo CC.OO.: carpeta secretariado confederal.

19 Archivo UGT: Circular 27 (confidencial) de la Comisión Ejecutiva de UGT, 24-7-76.

2. La UGT justificaba la creación de esta Alianza en Cataluña argumentando que la COS, a pesar de que se habia configurado en su documento de constitución como un organismo de unidad de acción en todo el Estado español, dejaba abierta la posibilidad de autonomía en el plano territorial o sectorial. UGT, $n^{\prime \prime} 373$, septiembre 1976. También la UGT quiso que la CNT formara 


\section{JORNADA DE PARO DEL 12 DE NOVIEMBRE}

Con el gobierno de Adolfo Suarez de julio de 1976 comenzaron a abrirse caminos de diálogo con los partidos de oposición y también con las organizaciones sindicales aún ilegales ${ }^{21}$, dando lugar a una serie de gestos, algunos de carácter simbólico y otros más efectivos como la concesión de la amnistía, todavía de carácter parcial, o la ratificación de los distintos convenios internacionales favorables a los derechos de los ciudadanos ${ }^{22}$. Sin embargo, los sindicatos interpretaron que el gobierno trataba de retrasar lo más posible la reforma sindical y ganar tiempo para sacar adelante su proyecto de reforma política. La chispa que encendió los ánimos de los sindicatos fueron las medidas económicas adoptadas por el Consejo de Ministros el 8 de octubre de 1976 y muy especialmente la suspensión del artículo 35 de la Ley de Relaciones Laborales. Ante esta agresión, los sindicatos convocaron una jornada de paro general para el 12 de noviembre de 1976 a través de la $\operatorname{COS}^{23}$. La huelga tuvo una respuesta importante ${ }^{24}$ (las cifras de huelguistas variaron según las diversas fuentes: para los sindicatos convocantes cerca de 2 millones y para el gobierno no más de 500.000 ) ${ }^{25}$, pero no con-

parte de la $\operatorname{COS}$, pero fue precisamente el sindicato anarquista quien se negó a participar en dicho organismo, aduciendo su incompatibilidad con CC.OO. Archivo UGT: Informe de la Comisión Ejecutiva de UGT presentado al Comité Federal, 9 y 10 de octubre de 1976.

21 Las entrevistas comenzaron con UGT el 19 de agosto de 1976 y siguieron con USO el 27 de agosto, con CC.OO. el 7 de septiembre, con ELA-STV, el 21 de septiembre y con el SOC, el 19 de octubre. El 8 de diciembre, el ministro de Relaciones Sindicales, Enrique de la Mata, se entrevistó con Nicolás Redondo; el 7 de febrero de 1977 con el secretariado de la CS de CC.OO. y el 23 de febrero con una delegación de USO. La Reforma Sindical, informès, $n^{\circ} 2,3,4$ y 5 , Ministerio de Trabajo/Instituto de Estudios Laborales y Seguridad Social (1976-1977).

22 ALVARO SOTO CARMONA: "Comisiones Obreras en la transición y consolidación democrática" en David Ruiz (dirección): Historia de Comisiones Obreras (1958-1988), Madrid, Siglo XXI, 1993, p. 452.

23 En la reunión del día 15 de octubre de la $\operatorname{COS}$ se acordó el llamamiento a una Jomada de Paro General para el día 12 de noviembre. El 18 de octubre, en otra reunión de la COS. se aprobó el documento de la convocatoria dirigido a todos los trabajadores. Archivo UGT: Circular 38 y 43 de la Comisión Ejecutiva de UGT de 26.10 .76 y 16.1 1.76. Según CC.OO., la UGT participó activamente en la preparación de la jornada de paro Archivo CC.OO.: Reunión del secretariado de la Coordinadora general de CC.OO. del 2.11.76.

24 Conviene señalar que pocos dias antes, el 27 de septiembre, tuvo lugar en el Pais Vasco y Navarra la mayor huelga general conocida en su historia: cerca de 600.000 trabajadores de un censo laboral no superior a 900.000 . Aunque el carácter de la huelga fue eminentemente político, pues la convocatoria se hizo para conmemorar la fecha de las ejecuciones de miembros del FRAP y ETA el año anterior, ponía de manifiesto el profundo descontento de los trabajadores ante la politica gubernamental, como lo demuestra que el mayor porcentaje de huelguistas el 12 de noviembre fue del Pais Vasco. Para una relación más detallada de la incidencia de los paros, ver Archivo CC.OO.: Informe de la jornada del $12 \mathrm{~N}$ y Mundo Obrero, 17.11.76.

25 Para la UGT, cel gobierno no pudo ocultar la importancia de la respuesta a la convocatoria del $12 \mathrm{~N}$, incluso las cifras reconocidas por el propio Ministerio de Gobernación (casi 600.00 huelgis- 
siguió paralizar el pais, ni que se retiraran los decretos del gobierno que implantaban nuevamente el despido libre y la congelación salarial, como tampoco que Suárez echara marcha atrás en su proyecto de ley de reforma política. Por otra parte, las medidas económicas del gobierno fueron muy del agrado de los empresarios que abogaban por una nueva ley de carácter laboral que acabara con lo que ellos Ilamaban "legislación paternalista", cuya máxima expresión era la ley de relaciones laborales y, sobre todo, su artículo 35 que impedía el despido laboral por motivos injustificados ${ }^{26}$.

Desde luego, la movilización del 12 de noviembre no se convirtió en la tan esperada huelga general que debia servir para imponer la ruptura, pero sí fue la jornada de lucha más importante que conoció el país en los últimos cuarenta años. Hay que tener en cuenta que en España no habia tradición de huelgas generales —ni siquiera en 1917 o 1934 se consiguió paralizar totalmente la población laboral-y que las organizaciones sindicales de oposición recién salidas del franquismo, conscientes de su debilidad y de las dificultades que suponía sacar adelante una acción de esa embergadura actuando desde la clandestinidad, circunscribieron el llamamiento a reclamaciones puramente laborales directamente relacionadas con las medidas económicas del gobierno. En la convocatoria no se hacia mención alguna ni a la ruptura democrática, ni a los objetivos políticos defendidos por la oposición, sólo se aludía a «que las medidas económicas aprobadas por el gobierno suponían un grave atentado a nuestros intereses y es preciso que los trabajadores demos una respuesta con una movilización masiva, unida, responsable y pacífica", al mismo tiempo que se exponía una plataforma reivindicativa en la que se reclamaba un aumento salarial de 6.000 ptas., el seguro de paro para todos los trabajadores, la amnistía laboral, la derogación de la legislación que admitía el despido libre, y la libertad sindical ${ }^{27}$.

tas), son enormes en nuestras condiciones de total falta de libertad sindical". Archivo UGT: Circular 43 de la Comisión Ejecutiva de la UGT, 16.11.76. Según Martín Villa, ministro de la Gobernación, la huelga del $12 \mathrm{~N}$ supuso un fracaso, no tanto por el número de huelguistas, sino porque los organizadores no consiguieron paralizar el pais y sobre todo por que en Madrid, donde más temía el gobierno que afectara la huelga, los transportes públicos y fundamentalmente el Metro trabajaron con cierta normalidad. RODolfo MARTin VILLA: Al servicio del Estado, Barcelona, Planeta, 1984, p. 56.

26 Declaraciones de Luis Alberto Salazar Simpson, presidente de la Unión de Empresarios del Sindicato Nacional del Combustible, en El Pais, 15-10-76.

"i Archivo UGT: "Convocatoria de la COS", Madrid, 18-10-76. En la plataforma común elaborada por la COS las reivindicaciones politicas eran de carácter muy general y no se hacia referencia a la ruptura. Se hablaba unicamente de la libertad de sindicación, amnistia politica y sindical y a los derechos de asociación, huelga, reunión, expresión y manifestación. Archivo USO: Carpeta "Dossier Coordinadora Sindical», documento, 3. 
Ni siquiera esta jornada del $12 \mathrm{~N}$ fue, como apuntaba la UGT, un ensayo de huelga general "que ha de hundir los últimos vestigios del franquismo" ${ }^{28}$, pues a partir de finales de 1976, y sobre todo desde el referendum de la reforma política, terminaron prácticamente las posibilidades de una ruptura política con el franquismo.

La huelga del 12 de noviembre no fue la única acción que protagonizó la COS. El organismo unitario tuvo un papel muy activo en la campaña abstencionista contra el referendum sobre la Ley de Reforma Política, aprobado por las Cortes en noviembre de 1976. La reforma de la seguridad social fue otro tema sobre el cual se manifestó la COS como organización representativa de los trabajadores. Por lo que respecta a la reforma sindical, aun cuando la COS como tal no emitió ningún comunicado, los tres secretarios generales de CC.OO., USO y UGT, Camacho, Zufiaur y Redondo, en una entrevista en diciembre de 1976 mantuvieron la misma postura, exigiendo el restablecimiento de la libertad sindical, la desarticulación de la CNS y la restitución del patrimonio sindical a los trabajadores.

A raíz del asesinato de los abogados laboralistas de Atocha y del secuestro del teniente general Villaescusa, la COS convocó para el día 26 de enero una jornada de paros generalizados, asambleas, minutos de silencio, etc. "desarrollados de una manera pacífica y serena, que no dé lugar a nuevas provocaciones" en respuesta a las posiciones desestabilizadoras del terrorismo de extrema derecha y de extrema izquierda ${ }^{29}$.

A través de su integración en la "Comisión de los 9 " el 17 de enero de 1977, la COS se incorporó a la negociación de la oposición democrática con el gobierno, quedando encargada, a través de una comisión técnica, de elaborar las bases de negociación en los aspectos sindicales y socio-económicos. El resultado de los trabajos de dicha comisión se tradujo en la elaboración de un documento que fue presentado a la Presidencia del Gobierno el 20 de abril de 1977, cuando la COS estaba prácticamente disuelta ${ }^{30}$.

\section{RUPTURA DE LA COS}

Poco después de la jornada del 12 de noviembre, comenzaron las mayores dificultades en el seno de la COS. UGT exigió a CC.OO. y

${ }^{28}$ UGT, $\mathrm{n}^{\circ} 375,2^{\mathrm{a}}$ quincena, noviembre 1976.

29 Archivo CC.OO.: Carpeta secretariado confederal.

30 F. Almendros Morcillo, E. Jimenez-Asenjo, F. Perez Amoros, E. Rojo Toraecilla: E! simdicalismo de clase en España (1939-1977), Barcelona, Península, 1978, pp. 272-273. 
USO que abandonaran definitivamente la OSE, argumentando que en algunas grandes empresas se estaban ya produciendo dimisiones de enlaces y jurados y que la patronal estaba dispuesta a negociar directamente con los sindicatos, todavía ilegales ${ }^{31}$. Era iluso pretender que CC.OO. y USO renunciaran a su estrategia dejando muy limitadas sus posibilidades de acción sindical en la empresa, pues no era cierto que la gran mayoría de los empresarios estuvieran dispuestos a reconocer a las centrales sindicales, prescindiendo de los jurados de empresa. No se podía confundir el hecho de que algunos empresarios participaran en coloquios con representantes de los sindicatos de oposición, con que la negociación colectiva pudiera desarrollarse al margen del Sindicato Vertical ${ }^{32}$.

Tanto para CC.OO. como para USO ${ }^{33}$, los enlaces y jurados seguían siendo necesarios y útiles, pues podian jugar un importante papel para acabar de liquidar la CNS y, lo que era más importante, impedir las maniobras neoverticalistas tendentes a apropiarse del patrimonio sindical y crear sindicatos amarillos desde las UTT ${ }^{34}$. Sólo dimitirían cuando se realizaran unas elecciones sindicales en plena libertad, pues -como argumentaban Nicolás Sartorius y Manuel Zaguirre- «no abandonaremos posiciones conquistadas hasta que no consigamos otras mejores" ${ }^{35}$.

31 UGT, $n^{\circ} 375,2^{a}$ quincena, noviembre 1976. “Hoy-decía Nicolás Redondo en su discurso en el XXVII Congreso del PSOE el 8-12-76- cuando son miles y miles los cargos sindicales que dimiten, cuando los propios empresarios constituyen sus sindicatos al margen de la Organización Sindical, para así negociar directamente con los trabajadores, es necesario seguir insistiendo ante los compañeros de otras organizaciones sindicales para que abandonen sus cargos como la mejor manera de acentuara la crisis de la OS oficial, ya en periodo de liquidación". UGT, $\mathrm{n}^{\circ} 377,2^{\mathrm{a}}$ quincena diciembre 1976 . Pero la propia UGT reconocía que no eran tantas las dimisiones y que la gran mayoria de ellas eran protagonizadas por militantes recientemente incorporados a la UGT. Archivo UGT: Circular 33 de la Comisión Ejecutiva, 27.9.76.

32 Los dias 11 y 12 de mayo de 1976 se celebró en el Palacio de Congresos de Madrid unas jornadas convocadas por Euroforum sobre el tema "hacia una nuevas relaciones en la empresa". El hecho de que en este encuentro sólo participaran los sindicatos ilegales, CC.OO., UGT y USO, y casi un centenar de empresarios y altos cargos directivos de empresas, fue interpretado por UGT como "una manifestación más del deseo y necesidad de amplios sectores del empresariado de dar de lado al sindicato vertical por no ser ya el instrumento adecuado para contener y reprimir las luchas obreras". Era una interpretación demasiado subjetiva, pues el propio sindicato socialista reconocía que los empresarios asistentes a estas jornadas se mostraron "muy dubitativos" a la hora de aceptar negociaciones al margen de los jurados de empresa. Archivo UGT: Circular de la Comisión Ejecutiva, 2.5.76.

3.3 Archivo USO: Circular interna $n^{\circ} 13$ del secretariado de USO, diciembre 1976. Declaración de comité ejecutivo de la USO de 15.6.76.

34 Jul.o SETIÉN: El movimiento obrero y el sindicalismo de clase en España (1939-1981), Madrid, Ediciones de la Torre, 1982, p. 45.

35 GDS, $n^{\circ} 69$, febrero 1977. Autonomia USO, $1^{\text {a }}$ quincena, diciembre 1976. 
En el trasfondo de la discusión subyacian los propios intereses de las centrales sindicales en un momento en que se disputaban enconadamente el espacio sindical. CC.OO. y USO sabian que cuanto más tiempo permanecieran en sus puestos los enlaces y jurados, más se prolongaría la situación privilegiada de sus organizaciones sindicales y mayores posibilidades de afiliación tendrían en un futuro inmediato. En este sentido, CC.OO. defendía el mantenimiento de los cargos sindicales porque tenían que ser la punta de lanza que permitiera ocupar ya los locales de la CNS y porque debian ser importantes elementos para reforzar el sindicato y lograr una afiliación masiva. "Los cargos representativos, de forma masiva deben afiliarse a CC.OO. y hacerlo público; es más las UTT en completo deben transformarse en sindicatos de CC.OO." ${ }^{36}$.

Por el contrario, UGT, que había rechazado históricamente su participación en el sindicalismo oficial, deseaba que desaparecieran cuanto antes los representantes sindicales de la OSE para poder estar en igualdad de condiciones con sus competidores. Buena prueba de que la dimisión de enlaces era algo puramente táctico para UGT era que dicho sindicato no exigía a sus propios militantes que abandonaran sus cargos sindicales. "No debemos rechazar - aconsejaba la Comisión Ejecutiva de la UGTlos contactos con actuales enlaces, jurados, etc. que se acercan cada vez en mayor número a la UGT. Por el contrario, a este respecto se impone una gran dosis de flexibilidad y de sentido común en la conciencia de que de esos enlaces y jurados - y fundamentalmente de los que se han movido como independientes - están saliendo excelentes militantes ugetistas... Pero sería absurdo exigirles sistemáticamente la dimisión de sus cargos en el verticalismo como condición previa a su ingreso en la Unión" ${ }^{37}$.

Las divergencias entre los sindicatos se centraban más que en el debate sobre los cargos sindicales en la distinta concepción que de la COS

30 Archivo CC.OO.: Documento del secretariado confederal titulado "Aspectos a tener en cuenta sobre la utilización de las posibilidades legales y la nueva legalidad", fechado a finales de 1976.

37 Archivo UGT: Circular 33 de la Comisión Ejecutiva de UGT, 27.9.76. Según R. FISHMAN en "El movimiento obrero en la transición: objetivos politicos y organizativos» en RE/S, $n$ " 26, abriljunio 1984 , p. 79 , el 19,8\% de los dirigentes de la UGT tuvo un cargo elegido en la OSE (datos de una encuesta realizada en 1980 entre los cargos elegidos en Madrid y Barcelona). En el análisis de esta cifra, aparentemente elevada, hay que tener en cuenta que la mayoria de los cuadros de USO que se integraron en UGT en 1977 eran enlaces o jurados de empresa. Para Agapito Ramos"la mayoria de los trabajadores, incluso los trabajadores socialistas, participaron en la OSE a pesar de que la CNT y la UGT dijeron que no". AgaPITO Ramos CuENCA: "Relaciones sindicales en el tranquismo y transición politica" en AA.VV: Cambio social y acción sindical en España (1975. 1983), seminario celebrado en la UIMP, 1983, Madrid, Fundación Largo Caballero, p. 17 
tenian. Mientras que para UGT su presencia en el organismo unitario respondía a una táctica sindical puramente coyuntural ${ }^{38}$, para CC.OO. y USO, su participación en la COS formaba parte de una estrategia concebida más a largo plazo, ligada a la desaparición de la CNS ${ }^{39}$ y a la constitución de un sindicato unitario ${ }^{40}$. Tan poca importancia daba la UGT a la COS, que dicha coordinadora apenas mereció mención a lo largo del discurso de Nicolás Redondo en el Congreso del PSOE, el 8 de diciembre de 1976; ni siquiera cuando habló de la jornada del $12 \mathrm{~N}$ hizo referencia al organismo que la convocó. Sin embargo, a lo que si aludió fue a la dimisión de enlaces y jurados, repitiendo una vez más los argumentos de su sindicato, y al rechazo del Congreso Constituyente propuesto por CC.OO. ${ }^{41}$.

A pesar de la falta de interés demostrada por el sindicato socialista, CC.OO. intentó revitalizar la COS proponiendo en su seno la elaboración de un proyecto reivindicativo que sirviera de base en la negociación de ios convenios y como instrumento unitario de lucha para conseguir la libertad sindical. Esperaban los dirigentes de CC.OO., sin mucha fe desde luego, que este programa común cfuera un instrumento importante en tanto que auténtica plataforma unitaria en torno a la cual consolidar desde ahora el fortalecimiento del sindicalismo español, lo que entre otras cosas exige acelerar la puesta en marcha de todos los elementos organizativos que acarrea la constitución de una central sindical y la potenciación de la COS como organismo unitario" 42. Analizaba, además, CC.OO. que la COS era un instrumento útil para forzar la legalización de las centrales sindicales e impedir cualquier maniobra que mantuviera en la ilegalidad a CC.OO. y al PCE ${ }^{43}$.

También USO tenía grandes esperanzas en la COS. Sus dirigentes pensaban que este organismo unitario, funcionando a pleno rendimiento y suficientemente estructurado por sectores, podía llegar a resolver la contradicción entre los comités de empresa y las secciones sindicales, como

38 Para la UGT, la COS «tenia que ser exclusivamente un organismo de unidad de acción destinado a precipitar la ruptura democrática y sindical". Archivo UGT: Intorme de la Comisión Ejecutiva al Comité Federal de 9 y 10 de octubre de 1976.

ay Para USO, la COS seria un instrumento muy válido para controlar el proceso de disolución de la CNS, el destino del patrimonio sindical, el futuro de sus funcionarios, el usufructo de locales, etc. Archivo USO: Circular interna 13 del secretariado de USO, diciembre 1976.

40 "La COS - decia CC.OO.- es un instrumento de unidad de acción en la perspectiva de unidad sindical de enorme importancia para nosotros". Archivo CC.OO.: Boletín interno del secretariado de CC.OO., no 1, enero 1977, p. 19.

4UGT, $n^{\circ} 377,2^{a}$ quincena, diciembre 1976.

42 GDS, $\mathrm{n}^{\circ} 70$, marzo 1977

43 Archivo CC.OO.: Resolución del secretariado confederal, 15.2.77. 
lo estaba haciendo el sindicalismo italiano, "en una combinación permanente - decia Manuel Zaguirre- entre la capacidad decisoria y deliberante en la elaboración de plataformas, programas, etc. que corresponde a los centros de trabajo (y por lo tanto a los comités de empresa), y esa globalidad que cubren en el papel las centrales sindicales" ${ }^{44}$.

Pero CC.OO. y USO se equivocaban al pensar que la COS serviría para fortalecer la unidad sindical y tendría una existencia fecunda, pues a los pocos meses de su creación, su muerte ya estaba anunciada. Los prolegómenos de su fallecimiento fueron presagiados por José Manuel Arija cuando pronosticó el inmediato fracaso de la COS, organismo al que calificaba de creliquia teórica de la unidad y no una respuesta a las necesidades organizativas del momento" ${ }^{45}$. La primera vez que UGT se desmarcó públicamente de la COS fue a primeros de marzo, cuando participó, junto a CNT, en una rueda de prensa para anunciar el propósito de luchar conjuntamente por la desaparición de los cargos sindicales. Este encuentro con los periodistas, en realidad, se convirtió en una auténtica diatriba del sindicato anarquista contra la COS, que no fue respondida por el representante ugetista, Victor Martínez Conde, alegando simplemente «que no era el momento oportuno para ello" ${ }^{46}$. El hecho de presentarse al lado de la CNT, enemiga acérrima de cualquier organismo unitario con CC.OO., sólo podía ser interpretado como una provocación y un intento de romper la COS.

El siguiente paso que dio la UGT fue negarse a firmar un llamamiento que tenia previsto lanzar la COS para dar respuesta a las recientes medidas laborales del gobierno. La razón de tal negativa, que suponía un serio impedimento para la existencia misma de la COS, estribaba en que CC.OO. y USO no estaban dispuestos a que sus cargos sindicales del vertical dimitieran ${ }^{47}$. A esta postura de la central socialista le siguieron

\footnotetext{
44 GDS, $n^{\circ} 70$, marzo 1977

45 José Manuel ARIJA: «El fracaso de la COS" en Diario 16, 25-2-77 y "Debate sindical» en Cambio 16, $n^{\circ}$ 276, 27-3-77.

40 El Pais, 9 marzo 1977.

47 En la reunión de la COS, celebrada el 10.3.77, en la que se debatió la posible convocatoria de una jornada de lucha por la libertad sindical y en protesta por el Decreto-Ley sobre Relaciones Laborales, la UGT exigió "que en el contexto de dicha campaña, uno de los puntos principales a presentar fuera el de la dimisión de los jurados y enlaces sindicales". Archivo UGT: Informe de la Comisión Ejecutiva presentado en la reunión del Comité Federal de UGT, el 26 y 27 de marzo de 1977. CC.OO. y USO, por su parte, en un comunicado conjunto, señalaron su extraneza ante el impedimento aducido por UGT, toda vez que su postura respecto a los cargos sindicales no fue obstáculo ni para la constitución de la $\operatorname{COS}$ ni para acciones unitarias como la del 12N. El Pais, 17-3-77.
} 
numerosas declaraciones en las que los dirigentes ugetistas hablaban de que la COS "si no estaba muerta, estaba moribunda" y era necesario crear otro organismo unitario que integrara al resto de las centrales sindicales ${ }^{48}$. Esto no era más que una maniobra que sólo pretendía torpedear la COS y justificar su posición anti-unitaria.

El 21 de marzo, en la reunión en que participaron la mayoría de las centrales sindicales, quedó definitivamente sentenciada la COS y rotas las posibilidades de llegar a un acuerdo conjunto para el llamamiento de una jornada de protesta obrera. USO y CC.OO., con el apoyo de la CSUT, convocaron para el 15 de abril una serie de movilizaciones, concretadas en asambleas de fábrica, manifestaciones, mítines y paros en favor de la libertad sindical y contra las recientes medidas gubernamentales en materia laboral ${ }^{49}$. Por otra parte, UGT y CNT anunciaron una semana de protestas, en apoyo a la libertad sindical y por la dimisión de enlaces y jurados. Aunque la jornada del 15 de abril no tuvo una especial repercusión (en ella participaron alrededor de 250.000 trabajadores según estimaciones de la prensa) ${ }^{50}$, entre otras cosas por el boicot de las propias Comisiones Obreras de Cataluña ${ }^{51}$, la semana de movilizaciones propugnada por UGT y CNT fue casi inexistente. Una vez más se ponía de manifiesto la escasísima capacidad de convocatoria de la central socialista en comparación con CC.OO. y USO.

Siete meses después de su constitución, la COS quedó rota tras la decisión del Comité Federal de UGT, reunido el 26 y 27 de marzo de 1977, de no asistir más a las reuniones del organismo unitario alegando que las divergencias tácticas entre UGT, CC.OO. y USO a la hora de definir la estrategia sindical para terminar con el verticalismo se habian hecho tan

48 El Pais, 18-3-77. A finales de marzo, la UGT afirmaba que "la COS atraviesa una profunda crisis, ya latente desde hace tiempo ya que al no haber conseguido llegar a ser un instrumen. to eficaz de lucha, sino una pura infraestructura, fundamentalmente dirigida más a lo espectacular que a lo eficaz, se añade los distintos y discrepantes criterios entre las centrales sindicales que la componen, criterios discrepantes sobre todo en relación a la dimisión o aprovechamiento de los cargos electivos de la OSE". Archivo UGT: Intorme de la Comision Ejecutiva presentado en la reunión del Comité Federal del 26 y 27 marzo de 1977.

4 Archivo CC.OO.: Carpeta secretariado confederal, comunicado conjunto CC.OO. USO de 23.3.77.

so Según CC.OO. y USO el número de trabajadores que siguieron la convocatoria fueron alrededor de 1.000.000; fuentes oficiales reducian la cifra a 95.000 , y la prensa estimaba la participación en torno a 250.000. El Pais, 16-4-77. GDS, $\mathrm{n}^{\circ} 72$, mayo 1977.

51 Francisco Giménez, secretario general de USO de Cataluña, denunció que las organizaciones de CC.OO. no habian participado en el llamamiento del 15 de abril. Asi lo reconocieron también dirigentes de la CONC que admitieron haber tenido importantes reticencias a la convocatoria de la fecha. GDS, $n^{\circ} 72$, mayo 1977. 
insalvables que no quedaba otra salida que el definitivo abandono de la COS por parte de la UGT, harta de exigir, sin resultado alguno, la dimisión de enlaces y jurados ${ }^{52}$. Los dirigentes ugetistas también justificaban su proceder argumentando el mal funcionamiento y la escasa implantación de la COS, constatando «que en la inmensa mayoría de las provincias y sectores de actividad, la COS no se había constituido, con lo que se incumplía uno de sus requisitos esenciales, tal y como fue concebida por UGT en el momento de su creación» ${ }^{53}$. No era esto sino una excusa que no hacía más que ocultar el escaso interés que la UGT había tenido siempre por desarrollar la COS. Fue principalmente la central socialista quien habia impedido crear organismos unitarios dependientes de la COS en numerosas empresas y sectores ${ }^{54}$. Como respondía Nicolás Sartorius "decir ahora que la COS ha fracasado porque se ha quedado en un acuerdo por arriba, raya en lo absurdo, pues es como si a un pájaro se le cortan las alas y luego se le mata porque no sirve para volar" ${ }^{55}$. Y eso había hecho la UGT, impedir volar a la COS para poder impulsar la pluralidad sindical, su verdadero objetivo.

En el fondo, la UGT no quería, con su presencia en la COS, contribuir por más tiempo a una política que claramente le perjudicaba, pues su acción sindical se veía muy dificultada por la actividad de los enlaces y jurados de CC.OO. y de USO en las empresas, que ejercían funciones de representación y negociación impidiendo, de hecho, cualquier alternativa de organización al margen del sindicato vertical. «Si CC.OO. y USO - decia la UGT - han creído poder utilizar la COS como pantalla para llevar adelante sus planteamientos particulares como organización, se han equivocado.

52 El Pais, 29-3-77. Archivo UGT: Informe de la Comisión Ejecutiva presentado a la reunión del ComitéFederal de UGT los dias 26 y 27 de marzo de 1977. Para CC.OO., no era éste un argumento serio "porque cuando la COS se constituyó, la diferencia existía y no fue obstáculo para esa constitución". JULIAN ARIZA: "¿Crisis de la COS?" en Mundo Obrero, 24.3.77

${ }_{53} 3$ UGT. $n^{\circ} 383,2^{-}$quincena de marzo de 1977. Archivo UGT: Informe de la Comisión Ejecutiva presentado en la reunión del Comite Federal del 29 de julio de 1977.

54 Como prueba del escaso interés de la UGT en impulsar la COS, CC.OO. denunciaba que dicha coordinadora no se habia podido constituir en Madrid por la intransigencia y el boicot de la UGT. GDS. $n^{\circ} 71$, abril 1977. La verdad es que la dirección de la UGT no hizo nada por favorecer la creación de la $\mathrm{COS}$ en ámbitos regionales o provinciales, se limitó a recordar a sus militantes que cen las bases del acuerdo de constitución de la COS no se establece ninguna obligación expresa de constituir la COS en los distintos niveles. De ahi, que las distintas Federaciones... quedan en libertad para constituir o no la $\operatorname{COS}$ en la zona de competencia...dependiendo de las condiciones objetivas y subjetivas que hagan posible la unidad de acción. Cada Federación podrá establecer alianzas de naturaleza distinta a la COS si asi lo estima conveniente". Archivo UGT Informe de la Comisión Ejecutiva presentado a la reunión del Comité Federal de UGT el 9 y 10 de octubre de 1976.

55 Informaciones, suplemento politico, 2.4.77. 
UGT ha respetado siempre, y respeta hoy, los compromisos adquiridos, pero no está dispuesta a avalar con su presencia en la COS las tácticas oportunistas de quienes sólo buscan el beneficio personal, con independencia absoluta de los verdaderos intereses del movimiento obrero" ${ }^{56}$.

Las reacciones de las otras centrales sindicales presentes en la COS fueron muy duras. En un comunicado conjunto firmado por CC.OO. y USO se recriminaba la actitud anti-unitaria de la UGT y se rechazaba rotundamente la dimisión de enlaces y jurados, defendiendo el mantenimiento de sus propias tácticas sindicales que habian contribuido decisivamente al auge del movimiento sindical y a la quiebra definitiva del sindicalismo vertical. No sólo no renunciaban a sus posiciones sindicales, sino que se sentían muy orgullosas de ellas y de su pasado sindical, explicando que "conscientes de que el resurgimiento del nuevo movimiento obrero de postguerra era imposible en el marco de la clandestinidad impuesta por la dictadura franquista, propugnamos y aplicamos desde siempre la táctica de utilización de cargos sindicales, de la combinación de la lucha legal e ilegal» y que se pudiera alcanzar un sindicalismo democrático "se debe en buena medida - afirmaba la declaración conjunta de CC.OO. y USO- a la utilización inteligente y combativa de los cargos sindicales" ${ }^{57}$.

Por su parte, CC.OO. recriminó al sindicato socialista no haber querido nunca la unidad sindical, ni siquiera la unidad de acción, y haber aceptado formar parte de la COS ante la presión unitaria de la clase trabajadora y ante la posibilidad de haberse quedado al margen de las movilizaciones impulsadas por el resto de las centrales sindicales. Acusó también a los dirigentes ugetistas de haberse plegado a las presiones de la CIOSL y de su presidente Otto Kersten que no había ocultado nunca su desagrado por la alianza táctica de la UGT con una organización sindical que consideraba marxista como CC.OO. Marcelino Camacho fue aún más allá, culpando de la ruptura de la COS a "poderosas presiones exteriores' que eran obra de un hombre de la CIA — seguramente se refería al secretario de los sindicatos americanos Irwing Brown - al que la organización le habia encargado la desunión de los trabajadores españoles, como "ya lo hizo en Francia - decía el secretario general de CC.OO.cuando la guerra fría, con la CGT» ${ }^{58}$. Esto demuestra el nivel en el que

56 UGT, $n^{\circ} 383,2^{2}$ quincena de marzo de 1977

57 GDS, $n^{\circ} 71$, abril 1977 y Autonomia-USO, 2 de abril 1977.

s8 Rueda de prensa de Marcelino Camacho en Sevilla. El Pais, 26-3-77. Estas declaraciones fueron rápidamente contestadas por la UGT en una carta pública que decia: Señor Camacho: Que la CIA existe no tiene vuelta de hoja. Y que la CIA manipula todo to manipulable, tampoco. 
algunos dirigentes sindicales desarrollaban el debate y el clima tan enrarecido entre CC.OO. y UGT. También Manuel Zaguirre, años más tarde, culpó a la ClOSL y al holding socialista, de machacar literalmente a la cos.

"Para alentar esa cruzada anti-COS - relata Zaguirre- vinieron a España los más variados personajes. Recuerdo a Otto Kersten, q.e.p.d., secretario general de la CIOSL entonces, experto en temas españoles y que descalificó groseramente la COS en los periódicos recurriendo al peligro comunista. Recuerdo la turbulenta entrevista mantenida por Mariano (Espúñez) y yo con Irwing Brown, un sindicalista norteamericano afincado en Europa desde no se sabe cuándo, del que tuvimos que escuchar lindezas como filocomunistas por negarnos a romper la COS y por afirmar rotundamente la soberania del sindicalismo español y su derechos a organizarse o unirse como quisiera para mejor expresar el papel de los trabajadores en el acceso a la democracia y en el contenido social de la misma" ${ }^{59}$.

La Unión Sindical Obrera hizo responsable a la UGT de haber roto la unidad de acción en un momento en que lo prioritario era conseguir la desaparición de la CNS y, al mismo tiempo, poner coto a la proliferación de las numerosas siglas sindicales que venían apareciendo desde finales de 1976 y, sobre todo, dificultar la creación de sindicatos amarillos, potenciados por el neoverticalismo ${ }^{60}$. Para conseguir estos objetivos, segun el criterio de la USO, la COS era un instrumento muy eficaz y con su desaparición se corría el riesgo de aumentar el confusionismo sindical ${ }^{61}$. José Maria Zufiaur, en su discurso ante el 1 Congreso de USO, el 7 de abril de

Pero de ahí a decir que la COS se ha roto porque la CIA asi lo ha dispuesto - vía UGT- va un gran abismo. ¿No cree? Consúltelo con su realidad, con su base, con su almohada, o si lo prefiere, con Phillip Agee". UGT, n 384, 13 de abril de 1977.

59 Manuel ZaguiRRE: “El sindicalismo español también es responsable de su propia crisis» en rev. El Proyecto (USO), $n " 4$, enero 1988, p. 51.

50 Además de las centrales tradicionales, CC.OO., USO, UGT, CNT y ELA-STV, existian otros sindicatos de reciente creación. 1) Desgajados de CC.OO.: a) Confederación de Sindicatos Unitarios de Trabajadores (CSUT), constituido el 6 de marzo de 1977 en Madrid, vinculado al Partido de los Trabajadores de España (PTE) y b) Sindicato Unitario (SU), cuyo congreso fundacional se celebró en mayo de 1977 y que estaba formado fundamentalmente por militantes de la Organización Revolucionaria de Trabajadores (ORT). 2) Nacionalistas: a) Asamblea de Trabajadores Vascos (LAB), ligado a la izquierda abertzale, b) Comité de Trabajadores Patriotas Comunistas (LAK), nacionalista radical vasco, c) Comisiones Obreras Anticapitalistas de Euskadi (COAE), creadas a finales de octubre de 1976. 3) Falangistas: Central Obrera Nacional Sindicalista (CONS), de tendencia hediliista. 4) Provenientes del Sindicato Vertical, entre ellos: Asociación Sindical Obrera (ASO), Confederación Sindical Obrera (CSO), Sindicato de Trabajadores de la Construcción (STC), Frente Obrero Unido (FOU) y la Confederación de Trabajadores y Técnicos Cristianos (CTC).

61 Autonomia-USO, 2-4-77. Debate Sindical I (USO), enero-tebrero 1977, pág, 26 
1977, se pronunció contundentemente por la permanencia de los cargos sindicales "hasta la disolución de la CNS y la convocatoria de elecciones sindicales libres" y advirtió al sindicato socialista que su salida de la COS podría conducirles al aislamiento sindical: "si los compañeros de la UGT han decidido hacer de la acción en solitario la regla - dijo el secretario general de la USO- y de la unidad de acción, la excepción... tienen que tener presente que si se excluyen de la acción común, de hecho se están excluyendo de la acción... Si ellos desean reforzarse y personalizarse, nosotros también. Pero no concebimos el desarrollo de nuestra organización como contradictorio con la unidad de acción. Al revés, la unidad de acción beneficia a todos $y$, por supuesto, en primer lugar, a la acción de los trabajadores" 62 .

La fundamental discrepancia entre UGT y el resto de las organizaciones que formaban la COS residía en la interpretación que cada sindicato hacia del organismo unitario ${ }^{63}$. Como escribía Manuel Chaves, miembro de la comisión ejecutiva de UGT, "en el seno de la COS se han manifestado divergencias profundas a la hora de concretar en la práctica las modalidades de nuestra lucha, divergencias que nacen a nivel táctico, pero que reflejan concepciones diferentes sobre los objetivos perseguidos" ${ }^{64}$. Pero éstos no podían ser los que se referian simplemente a la dimisión o no de los enlaces y jurados, sino que iban más allá y estaban directamente relacionados con la unidad o pluralidad sindical, verdadero meollo de la cuestión.

Para CC.OO., la COS se inscribía en la estrategia por conseguir la unidad sindical, era - como decía Nicolás Sartorius- "el intento más serio de unidad de los sindicatos democráticos, que permitía salir de la dictadura con las centrales unidas en la acción, en la perspectiva de la unidad organizada hacia la central unitaria de los trabajadores» ${ }^{65}$.

Por el contrario, para la UGT, la COS era sólo un instrumento para la unidad de acción entre las direcciones de las tres centrales sindicales, cuyo fin fundamental era romper con el sindicalismo oficial ${ }^{60}$. Asi, cuando

62 Archivo Uso: Congreso de USO, celebrado del 7 al 10 de abril de 1977.

6ł José María Zufiaur declaró años más tarde que «cada organización que en la cos estaba presente tenia su propio enfoque táctico de utilización, en cierta medida utilitarista, de la COS". José Maria Zufiaur: "Los sindicatos, elecciones sindicales y acción institucional" en AA.VV: Cambio social y acción sindical en España (1975-1983), Madrid, Fundación Largo Caballero, 1983, p. 46.

64 Informaciones, suplemento politico, 2-4-77.

65 informaciones, suplemento politico, 2-4-77

66. Entrevista con Nicolás Redondo en UGT, $n^{\circ} 377,2^{\circ}$ quincena de 1977. 
fue inminente la legalización de los sindicatos, los dirigentes ugetístas decidieron abandonar la COS estimando que ya se habian cumplido las funciones de esta coordinadora unitaria. Da la impresión, ademas, que la UGT habia formado parte de la COS presionada por el ambiente de lucha sindical de los primeros meses de $1976{ }^{67}$, tratando de recuperar el protagonismo histórico que ya no tenía ${ }^{68}$ y siguiendo los intereses del PSOE en Coordinación Democrática. Pero, cuando a principios de 1977 habían decrecido las movilizaciones obreras y habian desaparecido los organismos unitarios de la oposición (sólo quedaba la "Comisión de los 9"), ya no tenía demasiado sentido mantener la unidad en el ámbito sindical, máxime cuando los sindicatos occidentales, aliados de la UGT, no veían con buenos ojos la alianza con los comunistas de CC.OO. ${ }^{69}$.

El nacimiento de la COS fue difícil. Las conversaciones para su constitución duraron meses y en ellas - según reconocieron las centrales sindicales - no faltaron las zancadillas, los malentendidos y las actitudes oportunistas ${ }^{70}$. Su existencia no fue un camino de rosas, demostrándose finalmente la debilidad del planteamiento de unidad sindical tan ardorosamente defendido por CC.OO. ${ }^{71}$. Sin embargo, supuso una interesante experiencia unitaria que fue capaz de organizar la importante movilización del 12 de noviembre de 1976 y de aglutinar a las principales centrales sindicales en un momento clave de la transición, donde se jugaba en gran medida la libertad sindical y el futuro de los sindicatos ${ }^{72}$.

\footnotetext{
67 En abril de 1976, Luis Alonso Novo, dirigente de UGT, atirmaba que los trabajadores estaban "pidiendo a gritos" la constitución de una plataforma unitaria. GDS, n" 59, abril 1976, p. 27.

G8 JoSE MARIA ZUFIAUR: "Los sindicatos, elecciones sindicales y acción institucional" en AA.VV: Cambio social y acción sindical en España (1975-1983), Madrid, Fundación Largo Caballero, 1983, p. 46.

69 Según HOLM DeTLER-KOHLER: El movimiento sindical en España, Madrid, Fundamentos, 1995, p. 118, y WALTER L. BERNECKER: Gewerschaffen und Arbeitsbeziehungen in Spaniens transición, Frankfort, 1985, p. 442, la salida de UGT de la COS fue forzada por la Confederación Alemana de Sindicatos DGB y los sindicatos occidentales encabezados por Otto Kersten.

70 GDS, n'72, mayo 1977.

"Ludolfo Paramio: "Los sindicatos y la política en España. 1981-1992" en Alfonso Guerra y José Félix Tezanos (comps): La década del cambio, Madrid, Sistema, 1992, p. 523

72 Según ILSE MARIE FuHRER: Los sindicatos en España De la lucha de clases a estrategias de cooperación. Madrid, CES, 1996, pag. 101, la COS sirvió también «para demostrar al gobierno su fuerza y la unidad sindical y asi poder ejercer la presión necesaria para sus aspiraciones de democracia". Para MANuel ZaGuIRRE en "El sindicalismo español también es responsable de su propia crisis" en rev. El Proyecto (USO), $n^{\circ} 4$, enero 1988 , p. 50 , la COS fue "la respuesta más equilibrada y con más horizonte por delante, frente al unitarismo exacerbado de CC.OO. y el divisionismo a ultranza que pretendia UGT».
} 